\title{
SIMULTANEOUS DETERMINATIONS OF THE RESTING ARTERIO- VENOUS OXYGEN DIFFERENCE BY THE ACETYLENE AND DIRECT FICK METHODS ${ }^{1,2}$
}

\author{
BY CARLETON B. CHAPMAN, HENRY LONGSTREET TAYLOR, CRAIG BORDEN, \\ RICHARD V. EBERT, AND ANCEL KEYS WITH THE TECHNICAL ASSISTANCE OF \\ WALTER S. CARLSON

\begin{abstract}
(From the Laboratory of Physiological Hygiene and the Department of Medicine, University
\end{abstract} \\ of Minnesota, and the Veterans Administration Hospital, Minneapolis)
}

(Submitted for publication November 7, 1949; accepted, January 30, 1950)

Until 1941, when the technique for right heart catheterization was perfected by Cournand and associates (1), the acetylene method for measuring the arteriovenous difference was generally conceded to be the method of choice. The latter method, as devised by Grollman (2), is a relatively simple technique in which no surgical procedure is involved. The direct determination of the arteriovenous oxygen difference, on the other hand, requires the use of more complicated apparatus, the surgical exposure of a vein, and puncture of a femoral artery. In contrast to these disadvantages, the method possesses the great advantage of yielding values that are undoubtedly very close to the true values under the conditions of the procedure. It provides, therefore, a reliable standard to which the results obtained by other methods can be compared.

Unfortunately, the values for the normal basal arteriovenous oxygen difference, cardiac output, and cardiac index obtained by use of the two methods are not in agreement. Calculations from Grollman's data (3) show that the acetylene method, when applied to men between the ages of 20 and 30 , yields a mean value for the arteriovenous oxygen differences of $5.95 \pm 0.91 \mathrm{cc}$. per $100 \mathrm{cc}$. blood; for the cardiac output the value is $4.00 \pm 0.24$ liters per min. and for the cardiac index it is $2.21 \pm 0.42$ liters per sq. $\mathrm{m}$. per min. For the direct Fick method the corresponding values obtained by Cournand and co-workers were

\footnotetext{
1 Sponsored by the Veterans Administration and published with the approval of the Chief Medical Director. The statements and conclusions published by the authors do not necessarily reflect the opinion or policy of the Veterans Administration.

2 This work was performed under a cooperative agreement between the University of Minnesota and the $\mathrm{Na}$ tional Heart Institute, U. S. Public Health Service, Bethesda, Md.
}

$4.5 \pm 0.7$ cc. per 100 cc. blood, 5.6 liters per min., and $3.12 \pm 0.4$ liters per sq. $m$. per min., respectively. Values reported by other workers are substantially in agreement $(4,5)$. Cournand (6) concluded, on the basis of a comparison between his results and those obtained on comparable subjects by means of the ethyl iodide and acetylene techniques, that the direct Fick method yields values for the arteriovenous oxygen difference that are about 25 per cent lower than those obtained by the two foreign gas methods ( 25 per cent higher, in the case of the cardiac output and index).

The first attempt to compare the two methods was made by Baumann and Grollman (7) who, using direct puncture of the right heart for the collection of a venous blood sample, found the two techniques to yield almost identical values for the arteriovenous oxygen difference.

The most recent comparison of the two methods was carried out by Werkö, Berseus, and Lagerlöf (8), using the right heart catheterization procedure for the direct Fick determinations. As in the previous comparative studies, the two methods were applied in sequence rather than simultaneously, the direct Fick determination preceding the acetylene by a short interval. They found that the direct Fick method consistently gave lower arteriovenous oxygen differences (and higher cardiac outputs) than did the acetylene technique. Apart from this, there was apparently no relation between the results obtained by the two methods. Since none of the comparative studies to date have been truly simultaneous, the observed discrepancies in the values for the cardiac output still seem to be inadequately described.

It has been argued, with some justification, that basal conditions cannot be maintained during right heart catheterization and that values for the 
arteriovenous oxygen difference obtained under such conditions must be artificially high. If this is true, such values would not, therefore, be comparable to those obtained by the acetylene method which permits better control of factors tending to distort basal conditions.

The acetylene technique, on the other hand, is considered by some workers to give values for the arteriovenous oxygen difference that are too high because of early recirculation of acetylene $(9,10)$. Baumann and Grollman studied the question by puncturing the right heart and collecting blood samples at various intervals of time after the beginning of rebreathing of the acetylene mixture. On the basis of their findings, they concluded that unless the cardiac output is unduly high (over 7 liters per min.) recirculation can introduce an error of no more than 5 per cent if the gas sampling is concluded no later than $23 \mathrm{sec}-$ onds after the beginning of rebreathing. The most extensive and convincing study of the point is that by Werkö and co-workers, who, by means of right heart catheterization, withdrew serial blood samples from the pulmonary artery after rebreathing of an acetylene mixture was begun. They found that acetylene appeared in small amounts in the pulmonary arterial blood between 10 and 15 seconds after the beginning of rebreathing. Between 15 and 20 seconds after acetylene began to enter the lungs, pulmonary arterial blood contained about 1.5 volumes per cent of acetylene. They concluded, as did Baumann and Grollman, that the error due to recirculation of acetylene is small when the output of the heart is relatively low and large when it is high.

Forced rebreathing, as required by the acetylene technique, deserves close scrutiny in attempting to explain a systematic discrepancy between values for the arteriovenous oxygen difference as obtained by the acetylene method, on the one hand, and the direct Fick procedure, on the other. That such rebreathing does not affect the venous oxygen saturation in the time ordinarily required for the collection of the two gas samples has been shown by Werkö and co-workers. It has not yet been established, however, that the arterial oxygen saturation is unaffected by forced rebreathing ; in fact, the suggestion by Berggren (11) and by Lilienthal and colleagues (12) that some degree of intrapulmonary venous admixture, ow- ing probably to incomplete aeration of a small proportion of the alveoli, normally takes place under basal conditions, suggests the opposite. If this be true, forced rebreathing might temporarily raise the arterial oxygen saturation by reopening previously resting alveoli and reducing or abolishing the intrapulmonary venous shunt. Such an effect would increase the arteriovenous oxygen difference as measured by the acetylene technique; this, in turn, would result in an underestimation of the output of the heart. It should be noted that the increase in the arteriovenous oxygen difference would not actually reflect an increase in consumption of oxygen by the body tissues during the first few forced respiratory cycles. Neither would the apparent diminution in cardiac output during this period refer to an actual diminution in the amount of blood ejected per unit of time.

There remains to be considered the possibility that there is an error in the solubility coefficient for acetylene in blood as determined by Grollman (13) and as used in the formula for the calculation of the arteriovenous oxygen difference in the acetylene technique. Prior to Grollman's work Schoen (14) had found that under standard conditions $\left(37.8^{\circ} \mathrm{C}\right.$. and $760 \mathrm{~mm}$. $\mathrm{Hg}$ of acetylene) $760 \mathrm{cc}$. of acetylene are absorbed by one liter of blood. Grollman's studies fixed the figure at 740 cc. If the latter figure should prove to be too high, the solubility constant as used in the formula (0.00974) would also be too high as would the values for the arteriovenous oxygen difference. This in turn, when used in the Fick formula, would cause the value for the cardiac output to be too low.

The primary aims of the present investigation are to compare values for the arteriovenous oxygen difference and output of the heart obtained by means of the simultaneous application of the direct Fick and acetylene techniques; to re-examine the significance of recirculation in the acetylene technique; and to determine whether or not values obtained by the direct Fick method are significantly influenced by excitement due to right heart catheterization. Secondary aims include an inquiry into the effects of forced rebreathing in the arteriovenous oxygen difference and a consideration of certain points relative to the solubility of acetylene in blood. 


\section{METHOD}

Seven healthy male subjects, aged between 20 and 30 years, were employed for the study.

Prior to determining direct Fick and acetylene values simultaneously, the subjects were studied by means of the latter procedure alone, using the Grollman technique. For this purpose, the subjects reported to the laboratory early in the morning without breakfast. They were put to bed in a softly lighted, soundproof room containing virtually no scientific paraphernalia. The subject was instructed in the rebreathing procedure after which he was kept at complete rest for at least 30 minutes. The oxygen consumption was measured by means of a closed circuit apparatus during two consecutive test periods of six minutes each. Three consecutive acetylene determinations were then carried out, allowing a minimum of 20 minutes between each determination. The first gas sample was taken at the end of the third, and the second at the end of the sixth forced expiration.

The comparative studies were carried out several days after the initial acetylene determinations. The subjects were again in the fasting state. Every effort was made to allay anxiety during right heart catheterization but no sedative medication was used. After the catheter was in place in the pulmonary artery a Cournand needle was inserted into the femoral artery and a sample of systemic

TABLE I

Typical sequence in simultaneous determination of the output of the heart by the acetylene and direct Fick procedures

Begin rest
Right heart catheterization
Arterial puncture and sample (femoral)
Pulse rate 80
Blood pressure $124 / 80$
Acetylene rebreathing
First gas sample
Mixed venous blood sample
Second gas sample
Blood for acetylene determination
Blood for acetylene determination
Pulse rate 68
Blood pressure $134 / 80$

Oxygen consumption

$87: 00-107: 00$

Arterial sample (femoral)

109:00

Control blood for acetylene determination 109:00

Pulse rate 76

Blood pressure 134/86

Acetylene rebreathing

First gas sample

Mixed venous blood

Second gas sample

Blood for acetylene determination

Blood for acetylene determination

Pulse rate 66

Blood pressure 138/80

Rest period

112:00-137:00

Repeat output determinations

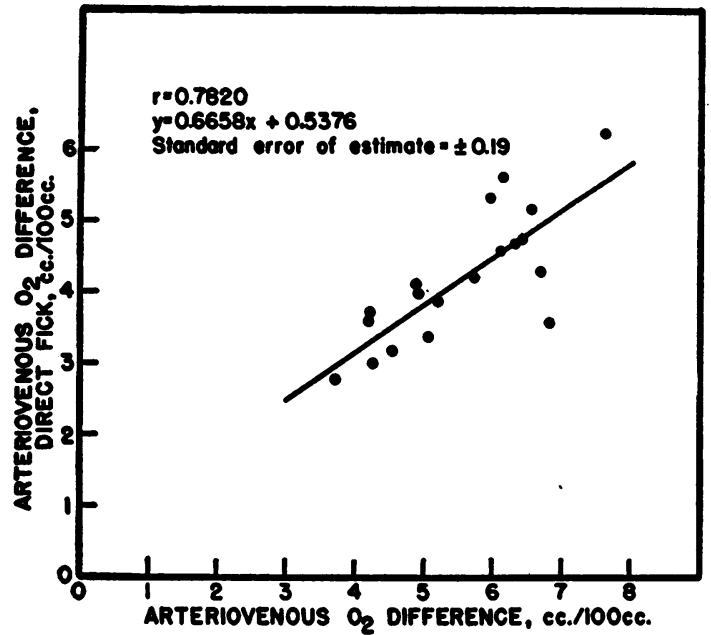

Fig. 1. The Relation between Values for the Resting Arteriovenous Oxygen Difference as Determined Simultaneously by the Acetylene and Direct Fick Methods (Values Obtained by the Acetylene Method Plotted on the X Axis)

arterial blood was taken. Immediately thereafter, a control sample was withdrawn from the pulmonary artery through the catheter. The mouthpiece and noseclip were then put in place and the subject was instructed to expire fully. When expiration was complete, the valve was turned and the patient began his first inspiration from the

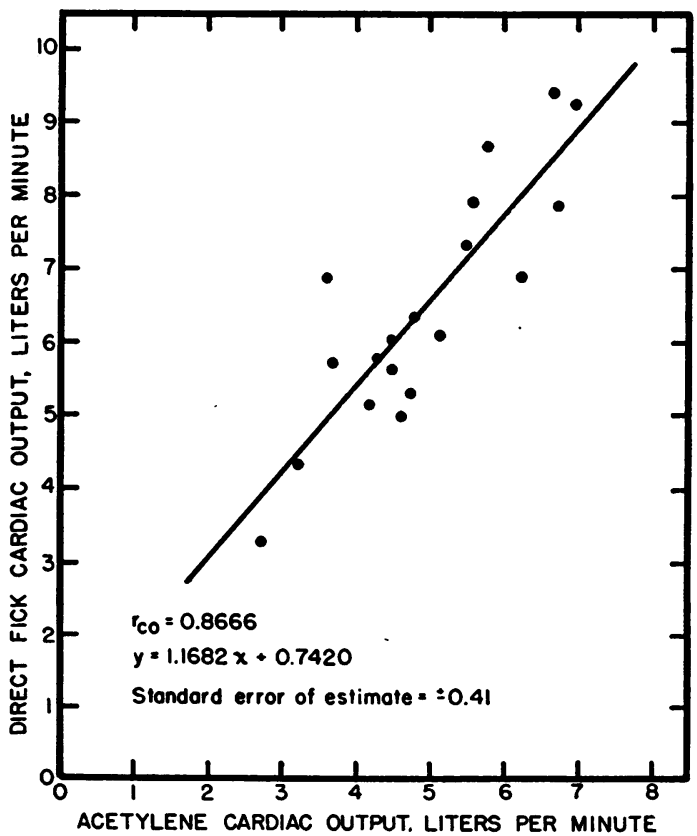

Fig. 2. The Relation between Values for the Resting Cardiac Output as Determined Simultaneously by the Acetylene and Direct Fick Methods 
bag containing the acetylene mixture. This point was taken as the zero point in time. At or soon after this point, the withdrawal of a mixed venous blood sample from the pulmonary artery was begun and at appropriate intervals, usually nine and 19 seconds, respectively, the first and second gas samples were collected. The latter were always taken in expiration. The withdrawal of the mixed venous blood sample always covered part or all of the interval between the collection of the two gas samples. As soon as the collection of the mixed venous blood sample was completed, additional blood samples for acetylene analysis were taken as rapidly as possible.

When the two gas samples had been obtained, the mouthpiece and noseclip were removed and, after a short interval, determination of the oxygen consumption was begun.

The entire procedure was repeated, usually twice, after an interval of 20 minutes. The Cournand needle was left in the femoral artery throughout the entire procedure and femoral arterial samples were taken for each direct Fick determination.

The sequence in a typical experiment is shown in Table I.

In order to obtain samples of pulmonary arterial blood for determination of acetylene content in the 10 to 20 second interval after the beginning of rebreathing, several special experiments, in which determination of the arteriovenous oxygen difference was omitted, were carried out. In the collection of these and other samples from the pulmonary artery a syringe was first attached to the catheter and a mixture of saline solution and blood was withdrawn. After collecting the mixture and a few cc. of pure blood, the initial syringe was detached and the sampling syringe substituted for it as quickly as possible. The exact points in time that corresponded to the beginning and end of the sample collection were noted. Seven to $8 \mathrm{cc}$. of blood were usually withdrawn in as many seconds so that the rate of withdrawal was ordinarily about one cc. per second. Since the volume contained by the catheter was $1.8 \mathrm{cc}$, a timing error of as much as 1.8 seconds may have occurred in the collection of each sample.

In order to determine the effect of forced rebreathing on the arterial oxygen content, five adult male subjects were employed. Femoral arterial puncture was carried out and a control sample of arterial blood was withdrawn. The subject then rebreathed a gas mixture from a bag identical with that used for the determination of the arteriovenous oxygen difference by the acetylene method. Two gas mixtures were used, one containing room air alone and the other room air plus 10 per cent acetylene. Fifteen seconds after the beginning of rebreathing a second sample of arterial blood was taken, the collection ending about 15 seconds later ( 30 seconds after the beginning of rebreathing). Thirteen such experiments were carried out on the five subjects.

Twenty-two tonometric equilibrations of venous blood with gas mixtures containing various partial pressures of acetylene were carried out in order to determine the solubility of acetylene in blood. Full details of this study are presented elsewhere (15).

TABLE II

Cardiac outputs and indexes determined simultaneously by the direct Fick and acetylene methods

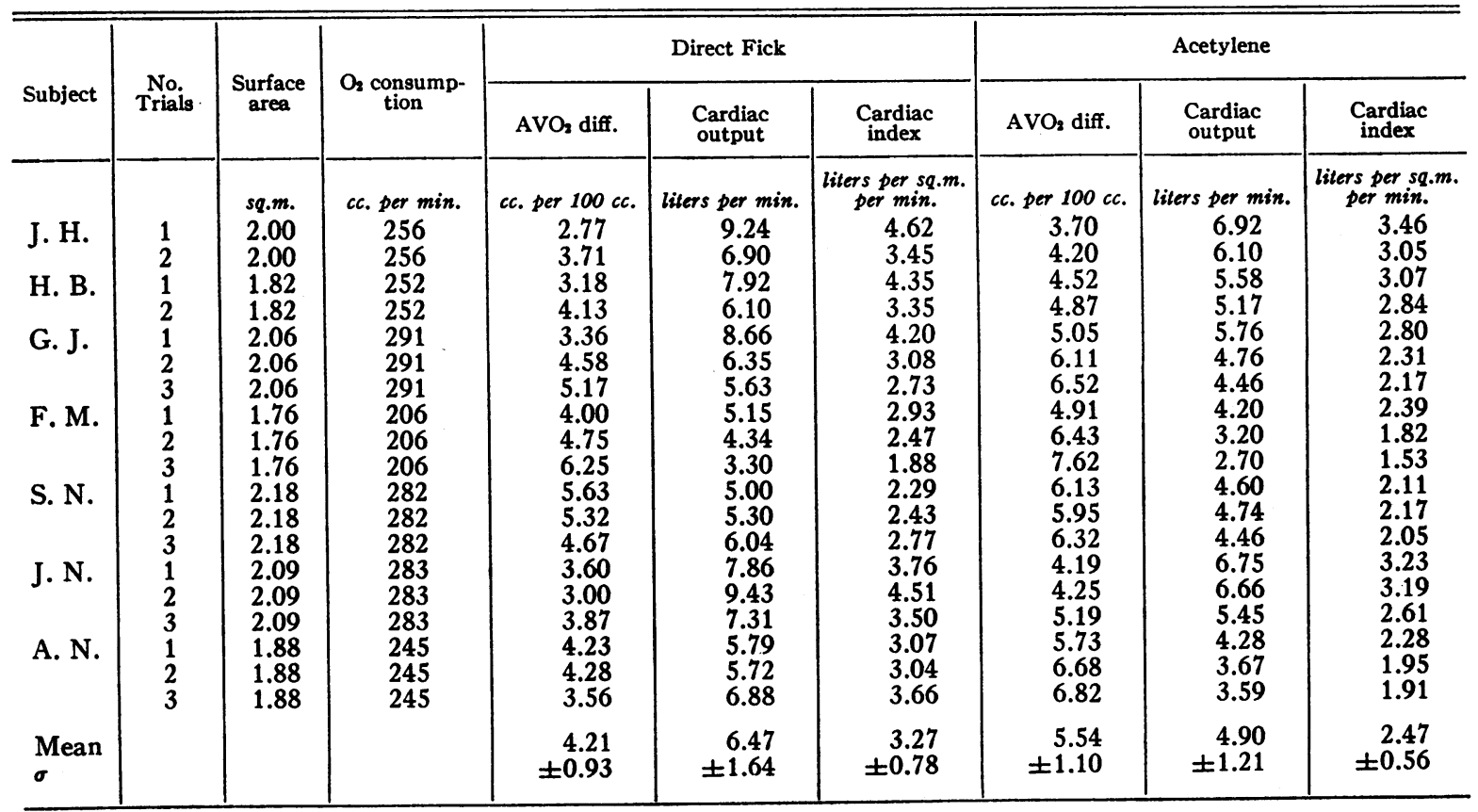


Blood gas analyses were done by the method of Van Slyke and Neill. The modification described by Grollman, Proger, and Dennig (16) was used in order to determine the amount of acetylene in blood. Gas samples were analyzed in the Haldane apparatus by the method embodying Grollman's modification (17).

\section{RESULTS}

Figures 1 and 2 and Table II present the results of the simultaneous comparison of the two methods for measuring arteriovenous oxygen difference and the output of the heart. Table II contains the values for the arteriovenous oxygen difference, cardiac output, and cardiac index for the entire series of determinations. Table III shows the arteriovenous oxygen differences, cardiac outputs, and cardiac indexes as determined on the same subjects by the acetylene method independently.

In Figure 3, the results of the analyses of pulmonary arterial blood for acetylene are plotted against the time intervals (beginning of rebreathing $=0$ time) at which the individual samples were drawn. In each instance, the mid-point of the period required for the collection of the sample is the time actually plotted.

Table IV presents the results of the experiments dealing with the effect of rebreathing on the arterial oxygen content.

Tonometric equilibration of blood with gas mixtures containing acetylene disclosed that the

TABLE III

Cardiac outputs and indexes determined by the acetylene method alone

\begin{tabular}{|c|c|c|c|c|c|c|}
\hline Subject & No. & $\begin{array}{c}\text { Surface } \\
\text { area }\end{array}$ & $\begin{array}{l}\mathrm{O}_{2} \text { con- } \\
\text { sumption }\end{array}$ & $\begin{array}{l}\mathrm{AVO}_{2} \\
\text { diff. }\end{array}$ & $\begin{array}{l}\text { Cardiac } \\
\text { output }\end{array}$ & $\begin{array}{l}\text { Cardiac } \\
\text { index }\end{array}$ \\
\hline & & sq. m. & $\begin{array}{c}\text { cc. per } \\
\text { min. }\end{array}$ & $\begin{array}{l}c c . \text { per } \\
100 \text { cc. }\end{array}$ & $\begin{array}{c}\text { liters per } \\
\text { min. }\end{array}$ & $\begin{array}{l}\text { liters per } \\
\text { sq. m. per } \\
\text { min. }\end{array}$ \\
\hline J. H. & 1 & 2.06 & 225 & 5.43 & 4.14 & 2.01 \\
\hline H. B. & 1 & $\begin{array}{l}2.00 \\
1.88\end{array}$ & $\begin{array}{l}225 \\
239\end{array}$ & 4.88 & $\begin{array}{l}4.21 \\
4.90\end{array}$ & 2.61 \\
\hline & 2 & 1.88 & 239 & 6.12 & 3.91 & 2.08 \\
\hline G. J. & 1 & 2.09 & 255 & 4.71 & 5.41 & 2.59 \\
\hline & 2 & 2.09 & 255 & 6.07 & 4.20 & 2.01 \\
\hline F. M. & 1 & 1.78 & 195 & 4.86 & 4.01 & 2.25 \\
\hline & 2 & 1.78 & 195 & 5.81 & 3.36 & 1.89 \\
\hline S. N. & 1 & 2.20 & 268 & 6.32 & 4.24 & 1.93 \\
\hline & 2 & 2.20 & 268 & 7.06 & 3.80 & 1.73 \\
\hline J. N. & 1 & 2.09 & 303 & 5.15 & 5.88 & 2.81 \\
\hline & 2 & 2.09 & 303 & 5.55 & 5.46 & 2.61 \\
\hline A. N. & 1 & 1.88 & 250 & 6.65 & 3.76 & 2.00 \\
\hline $\begin{array}{l}\text { Mean } \\
\sigma\end{array}$ & & & & $\begin{array}{r}5.68 \\
\pm 0.73\end{array}$ & $\begin{array}{r}4.41 \\
\pm 0.76\end{array}$ & $\begin{array}{r}2.20 \\
\pm 0.34\end{array}$ \\
\hline
\end{tabular}

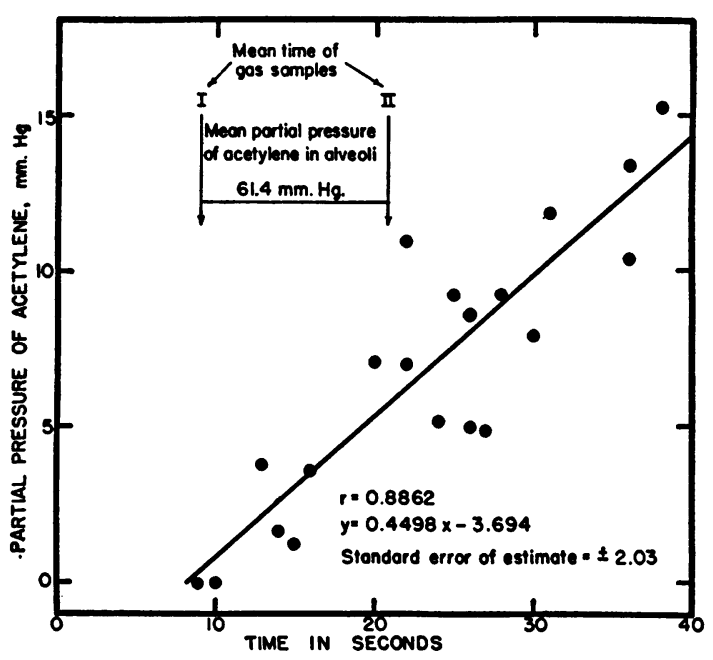

Fig. 3. The Appearance of Acetylene in Pulmonary Arterial Blood after the Beginning of Rebreathing

amount of acetylene that will dissolve in one liter of blood at $37.8^{\circ} \mathrm{C}$. and $760 \mathrm{~mm}$. $\mathrm{Hg}$ of acetylene is $700.2 \mathrm{cc}$.

Analysis of the data by means of standard statistical techniques was carried out where indicated. The high degree of correlation between the simultaneously determined values for the arteriovenous oxygen difference and the output of the heart as measured by the direct Fick and the acetylene methods are indicated in Figures 1 and 2. When the figures for the cardiac index were used, the correlation coefficient was 0.84 .

TABLE IV

The arterial oxygen content before and during rebreathing of room air and of room air containing 10 per cent acetylene

\begin{tabular}{|c|c|c|c|c|c|c|}
\hline \multirow{2}{*}{ Subject } & \multirow{2}{*}{ Exp. } & \multirow{2}{*}{ Gas mixture } & \multicolumn{2}{|c|}{ Arterial $\mathrm{O}_{2}$ content } & \multirow{2}{*}{ Diff. } & \multirow{2}{*}{ Diff. } \\
\hline & & & Control & Rebreathing & & \\
\hline \multirow{4}{*}{$\begin{array}{l}1 \\
2\end{array}$} & \multirow{13}{*}{$\begin{array}{l}1 \\
1 \\
2 \\
3 \\
1 \\
2 \\
3 \\
1 \\
2 \\
3 \\
1 \\
2 \\
3\end{array}$} & \multirow{13}{*}{ 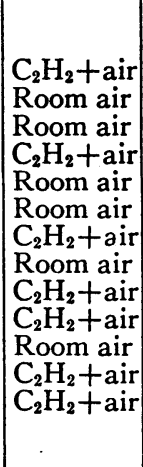 } & $\begin{array}{c}\text { vol. } \\
\text { per cent }\end{array}$ & vol. per cent & pol. & per cent \\
\hline & & & & & 0.32 & +1.74 \\
\hline & & & & & 0.20 & \\
\hline & & & 15 . & & -0.17 & -1.0 \\
\hline \multirow[t]{3}{*}{3} & & & 17. & 18 & 0.88 & $t$ \\
\hline & & & 17. & & 0. & \\
\hline & & & 17. & 1 & 0.04 & 7 \\
\hline \multirow[t]{3}{*}{4} & & & 19. & & 0 . & + \\
\hline & & & 18. & & 0. & \\
\hline & & & 18.36 & 18 & 0.31 & \\
\hline \multirow[t]{2}{*}{5} & & & 17.82 & & 0.03 & +0.17 \\
\hline & & & 17. & & $\begin{array}{r}0.06 \\
-016\end{array}$ & \\
\hline lean & & & 17.52 & 17.82 & 0.28 & +1.55 \\
\hline
\end{tabular}




\section{DISCUSSION}

Figures 1 and 2 and Table II leave no doubt that there is a considerable difference between the values for the arteriovenous oxygen difference and the cardiac output obtained under basal conditions by the acetylene technique, on the one hand, and the direct Fick procedure on the other. The results of the present studies are substantially in agreement with the values for the basal arteriovenous oxygen difference and cardiac index obtained by Grollman with the acetylene method and by Cournand and associates with the direct Fick method. The amount by which the direct Fick value differs from the acetylene figure is strikingly constant from test to test and individual to individual. Expressed in another way, the values for the arteriovenous oxygen difference obtained by the direct Fick method may be expected to run about 24 per cent less than those obtained by the acetylene procedure. Knowing one of these values, one can calculate the other by use of the formula :

$\mathrm{AVO}_{2}$ diff., direct Fick $=0.6638\left(\mathrm{AVO}_{2}\right.$ diff., acetylene) +0.5384 ,

the standard error of the estimate being \pm 0.19 cc. per $100 \mathrm{cc}$. blood. Comparison of Figures 1 and 2 shows that when the values for the arteriovenous oxygen difference are plotted against each other, the resulting correlation coefficient, although significantly high, is lower than that obtained when the values for the cardiac output are so treated. The value $r_{c o}(0.87)$ is probably artificially high; since both methods are primarily techniques for determining the arteriovenous oxygen difference, the best estimate of the relation between them is that given in Figure $1(r=0.78)$.

The demonstration of a high degree of correlation between values obtained by the two methods is in contrast to the findings of Werkö and coworkers. Their work confirmed the fact that the direct Fick procedure yields values for the cardiac output that are consistently higher (about 42 per cent in their hands) than those obtained by the acetylene method but the differences they observed were quantitatively unpredictable from determination to determination. The experimental error in the acetylene method was found by them to be twice as large as that in the direct Fick method (coefficient of variation 20.2 and 10.2 per cent, respectively). Calculation of the correlation coefficient from their data, by plotting the acetylene arteriovenous oxygen differences against the corresponding direct Fick values $(\mathrm{N}=22)$ gives a value of 0.26 . The indication is that the absence of significant correlation between the two methods as applied by the Swedish workers is due, in large measure, to method error in the acetylene technique. It should be noted, however, that in at least three, and probably in four, of their 22 trials the direct Fick values for the cardiac output were over 11 liters per min., at which levels no foreign gas method can be expected to yield accurate results without special modifications. One of the lowest acetylene values in their series (3.53 liters per min.) was obtained shortly after a direct Fick output of 11.10 liters per min. was recorded. Furthermore, the mean cardiac output calculated from their data $(7.7 \pm 2.8$ liters per min.) for the direct Fick techniques is considerably higher, and the mean arteriovenous oxygen difference ( $3.5 \pm 1.0 \mathrm{cc}$. per $100 \mathrm{cc}$. blood) is lower than that obtained by other workers using the method separately, indicating that the study was probably not a basal one. Another difficulty in evaluating their results lies in the fact that the determinations were not simultaneous. Although the acetylene determinations followed the direct Fick determinations by no more than a few minutes, such an interval is probably long enough to permit considerable change in the cardiac output to occur. Finally, in an effort to minimize the error due to faulty mixing of the gases in the lung-bag system, they collected alveolar gas samples somewhat later than is customary. There is good evidence, however, that satisfactory mixing occurs in something less than 10 seconds (18) and that significant delay beyond the points recommended by Grollman for the collection of gas samples is unwarranted.

Since, under basal conditions, there is a reasonably constant difference between the values obtained by the acetylene and direct Fick methods, some explanation for the difference must be sought. On the face of the matter, one of the most plausible explanations is that which invokes excitement to account for the fact that the direct Fick results are higher than those obtained by the acetylene technique. The present results do not support such an explanation. The mean value for the cardiac 
index obtained by use of the acetylene technique under conditions made necessary by the right heart catheterization procedure $(2.47 \pm 0.56$ liters per sq.m. per min.) is virtually identical with that obtained on the same subjects by the acetylene method alone under entirely different, and probably less alarming, experimental conditions $(2.20$ \pm 0.44 liters per sq.m. per min.). In four of the seven subjects, the initial acetylene and direct Fick values for the cardiac output and index were somewhat higher than the second or third value, suggesting the presence of a trend. Such a phenomenon has been noted before and may be the result of excitement related in part to femoral puncture. In the present study, however, the small difference between the two means (2.47 and 2.20 liters per sq.m. per min.) was not significant when tested statistically ( $\mathrm{T}$ test). This clearly indicates that the excitement occasioned by right heart catheterization was not sufficient to alter the acetylene, and by inference the direct Fick, cardiac outputs and indexes significantly for a sample of this size. If the difference between the values obtained by independent use of the two methods is, in fact, due to excitement, the methods should yield virtually identical values when applied simultaneously. This was not the case, and the assumption that the discrepancy between the values obtained by the two techniques is due wholly to excitement is therefore untenable.

The possibility that early recirculation of acetylene may introduce serious error has received considerable attention from previous investigators. There is no doubt that measurable quantities of acetylene are present in pulmonary arterial blood during the interval between the collection of the two gas samples required by the acetylene technique (Figure 3). In the present work, the mean times for collection of the first and second gas samples were nine and 19 seconds, respectively. Acetylene began to appear in pulmonary arterial blood at about 10 seconds and at 19 seconds the partial pressure of acetylene in the blood entering the lungs was about $6 \mathrm{~mm}$. $\mathrm{Hg}$, allowing for the timing error due to the column of blood contained in the catheter. The mean partial pressure for the period between the collection of the two gas samples was about $61 \mathrm{~mm}$. Hg. Hence, when gas samples are taken at nine and 19 seconds, recirculation may introduce an error of about 5 per cent.
When the collection times are 14 and 24 seconds, as recommended by Grollman, the error may conceivably be as much as 10 per cent but to explain an error of 24.5 per cent on this basis the gas samples would have to be collected no earlier than 35 and 45 seconds.

Another contributing factor may be the effect of forced rebreathing on the arteriovenous oxygen difference as measured by the acetylene method. The present studies show, qualitatively at least, that there is a slight increase in the arterial oxygen content as a result of forced rebreathing of room air or of a mixture containing room air and 10 per cent acetylene. Although the data do not permit a precise quantitative definition of the amount of increase due to forced rebreathing, the mean increase observed was 0.28 volumes per cent. In the acetylene method this factor, by raising the arterial oxygen content, must cause an increase in the amount of oxygen taken up from the lungbag system in the interval between the collection of the two gas samples. This, in turn, produces an artificially high arteriovenous oxygen difference and an underestimation of the cardiac output. The amount by which forced rebreathing causes the acetylene technique to underestimate the output of the heart is about 7 per cent. An error of the same magnitude would be introduced into the direct Fick method if the arterial blood samples were collected during rebreathing. Since, in the present studies, the arterial blood samples for the direct Fick determinations were collected just prior to rebreathing, no such error has to be reckoned with.

In addition to the error contributed by recirculation of acetylene and the effect of rebreathing on the arterial oxygen content there remains the possibility of an error in the solubility coefficient for acetylene in blood. The tonometric equilibrations carried out in the present study indicate that Grollman's figure is too high. By applying a regression formula calculated from the data the figure 700.2 cc. of acetylene per liter of blood (at $37.8^{\circ} \mathrm{C}$. and $760 \mathrm{~mm}$. $\mathrm{Hg}$ of acetylene) was obtained. The solubility coefficient as used in the formula for the arteriovenous oxygen difference thus becomes 0.00921 instead of 0.00974 . Use of the smaller solubility coefficient reduces the values for the arteriovenous oxygen difference by about 6 per cent 
and increases the values for the cardiac output by the same amount.

The discrepancy of 24 per cent between values obtained by the direct Fick method on one hand and the acetylene technique on the other is, therefore, a composite figure. Recirculation of acetylene, the effect of rebreathing on the arterial oxygen content, and an error in the solubility coefficient of acetylene for blood account for most or all of the discrepancy. The error in the solubility coefficient is a constant one and the other two factors are, in all probability, variable to some extent. In the case of a high cardiac output, for example, recirculation may contribute an error that is somewhat greater than 5 per cent. When the arteriovenous oxygen difference is determined under basal conditions by means of the acetylene method the regression formula given in Figure 1 will suffice to predict the corresponding direct Fick value if the Grollman formula for the arteriovenous oxygen difference is used. Use of the formula in Figure 2 may be similarly applied to values for the output of the heart obtained by the acetylene method. Since the solubility coefficient for acetylene in blood used by Grollman (0.00974) is too high, the value 0.00921 should be employed in the formula for the arteriovenous oxygen difference. When the change is made the correct equation for predicting the basal direct Fick output from a given basal acetylene value is: Direct Fick output $=1.106$ (acetylene output) +0.7526 , and the standard error of the estimate is 0.41 liters per min.

Under basal conditions, therefore, the acetylene method is a relatively reliable means of measuring the arteriovenous oxygen difference and the values obtained may be converted to the corresponding direct Fick values with reasonable accuracy if the sources of error in the acetylene method are taken into account.

\section{CONCLUSIONS}

1. There is a linear relationship and a high degree of correlation between resting values for the arteriovenous oxygen difference and the cardiac output obtained simultaneously by the acetylene and direct Fick methods.

2. Values for the arteriovenous oxygen difference obtained by the use of the direct Fick technique consistently run about 24 per cent less than those obtained with the acetylene method.

3. Right heart catheterization disturbs basal conditions in adult male subjects little more than does the acetylene procedure and the assertion that the direct Fick technique regularly gives high values for the resting output of the heart is untenable.

4. Measurable quantities of acetylene begin returning to the lungs about 10 seconds after the beginning of rebreathing but the error introduced, under basal conditions, into the acetylene technique as ordinarily applied is no more than 5 per cent.

5. Forced rebreathing, as used in the acetylene method, produces an increase in the arterial oxygen content of about 0.28 volumes per cent and causes the acetylene method to overestimate the arteriovenous oxygen difference. The factor may account for nearly one-third of the discrepancy between values obtained by use of the direct Fick method on the one hand and the acetylene technique on the other.

6. The amount of acetylene that will dissolve in a liter of blood at $37.8^{\circ} \mathrm{C}$. and $760 \mathrm{~mm}$. $\mathrm{Hg}$ of acetylene is $700.2 \mathrm{cc}$. and the solubility coefficient for use in the formula for the arteriovenous oxygen difference is 0.00921 .

\section{BIBLIOGRAPHY}

1. Cournand, A., Riley, R. L., Breed, E. S., Baldwin, E. de F., and Richards, D. W., Jr., Measurement of the cardiac output in man using the technique of catheterization of the right auricle or ventricle. J. Clin. Invest., 1945, 24, 106.

2. Grollman, A., The determination of cardiac output of man by the use of acetylene. Am. J. Physiol., 1929, 88, 432.

3. Grollman, A., VI. Physiologic variations in the cardiac output of man. The value of the cardiac output of the normal individual in the basal, resting condition. Am. J. Physiol., 1929, 90, 210.

4. Warren, J. V., Stead, E. A., Jr., and Brannon, E. S., The cardiac output in man: A study of some of the errors in the method of right heart catheterization. Am. J. Physiol., 1946, 145, 458.

5. Ebert, R. V., Borden, C. W., Wells, H. S., and Wilson, R. H., Studies of the pulmonary circulation. I. The circulation time from the pulmonary artery to the femoral artery and the quantity of blood in the lungs in normal individuals. J. Clin. Invest., 1949, 28, 1134. 
6. Cournand, A., Measurement of the cardiac output in man using the right heart catheterization. Federation Proc., 1945, 4, 207.

7. Baumann, H., and Grollman, A., Uber die theoretischen und praktischen Grundlagen und die klinische Zuverlässigkeit der Acetylenmethode zur Bestimmung des minutenvolumens. Ztschr. f. klin. Med., 1930, 115, 41.

8. Werkö, L., Berseus, S., and Lagerlöf, H., A comparison of the direct Fick and the Grollman methods for determination of the cardiac output in man. J. Clin. Invest., 1949, 28, 516.

9. Gladstone, S., Cardiac Output and Arterial Hypertension. S. Gladstone, New York, 1935.

10. Hamilton, W. F., Spradlin, M. C., and Saam, H. G., Jr., An inquiry into the basis of the acetylene method of determining the cardiac output. Am. J. Physiol., 1932, 100, 587.

11. Berggren, S., The oxygen deficit of arterial blood caused by non-ventilating parts of the lung. Acta physiol. Scandinav., 1942, 4, Suppl. 11, 1.

12. Lilienthal, J. L., Jr., Riley, R., Proemmel, D., and Franke, R., An experimental analysis in man of the oxygen pressure gradient from alveolar air to arterial blood during rest and exercise at sea level and at altitude. Am. J. Physiol., 1946, 147, 199.

13. Grollman, A., The solubility of gases in blood and blood fluids. J. Biol. Chem., 1929, 82, 317.

14. Schoen, R., Zur Kenntnis der Acetylenwirkung. II. Mitteilung. Die Löslichkeit von Acetylen in Wasser und Blut. Ztschr. f. physiol. Chem., 1923, 127, 243.

15. Taylor, H. L., Keys, A., and Carlson, W., The physical and physiological solubility of acetylene in blood. 1949. In preparation.

16. Grollman, A., Proger, S., and Dennig, H., Zur Bestimmung des Minutenvolumens mit der Azetylenmethode bei Arbeit bei normalen und kranken Menschen. Arch. f. exper. Path. w. Pharmakol., 1931, 162, 463.

17. Grollman, A., The Cardiac Output of Man in Health and Disease. Charles C. Thomas, Springfield, Ill., 1932.

18. Christensen, E. H., Beiträge zur Physiologie schwerer körperlicher Arbeit. III. Mitteilung: Gasanalytische Methoden zur Bestimmung des Herzminutenvolumens in Ruhe und während körperliche Arbeit. Arbeitsphysiol., 1931, 4, 175.

\section{ERRATUM}

On page 480 in the April issue of the Journal the character $\bar{v}$ is missing in two lines at the top of the page in the left-hand column. Line 3 should correctly read: " $\bar{v} m$ is the concentration of bound thiocyanate." Line 10 should read: ". . . and since equation 4 relates $\bar{v}$ to. . . . " 